\title{
A CRIANÇA EXCEPCIONAL
}

* Maria da Penha dos Santos

RBEn/11

SANTOS, M.P. - A criança excepcional. Rev. Bras. Enf.; DF, 33 : 236-241, 1980.

R E S U M O

O autor comenta o conceito de excepcionalidade e faz considerações sobre a compreensão, aceitação e as formas de atendimento à criança excepcional. $O$ indivíduo excepcional é considerado um ser fora do contexto, um limitado, porque vivemos numa sociedade onde todos têm um papel préestabelecido a exercer. Mas, o problema do excepcional é, acima de tudo, um problema humano e que atinge todo o complexo econômico-social.

\section{INTRODUÇAOO}

- No Ano Internacional da Criança é Justo e válido que reflitamos também sobre um dos grandes e graves problemas da criança: A Criança Excepcional.

Temos no Brasil mais de $95 \mathrm{mil}$ pessoas excepcionais, constituindo um problema, principalmente humano, da maior relevância e que atinge todo o complexo econômico-social.
O que é um excepcional? Temos idéias bem diversas a este respeito e nelas sempre paira um estigma, pois, pensamos, sentimos o excepcional, empregando termos como deficiente, diferente, excepcional e semelhantes. A idéia de que o deficiente, seja físico, mental ou social é um limitado, um ser fora do contexto, está firmemente associada à idéia de uma sociedade em que todos têm um papel pré-estabelecido a exercer. Na revolução industrial mudase a concepção do que o homem faz na sociedade; ele é, agora, uma peça da produção. A competição, realizada em todos os níveis, estimula o Império do mais forte. $\mathrm{E}$ os incapazes disto? São deficientes porque não eficientes, excepcionais porque fora do contexto econômico-social, limitados porque não podem atingir, como seus concorrentes, a produção máxima. São, portanto, um estorvo, dignos de desprezo ou de compaixão, apenas tolerados pela sociedađe.

Mas, felizmente, novas prespectivas estão se abrindo na assistência aos ex-

\footnotetext{
" Professora Títular da Disciplina "Enfermagem Psiquiátrica" do Departamento de Enfermagem da Faculdade de Medicina da Universidade Federal de Juiz de Fora e Psicóloga da SELF - Clínica de Psicologia de Juiz de Fora.
} 
SANTOS, M. P. - A criança excepcional. Rev. Bras. Enf.; DF, 33 : 236-241, 1980.

cepcionais. A sociedade está reconhecendo a realidade da existência deles e resolve ampará-los e protegê-los. Estamos vivendo um período de transição, do paternalismo excessivo a uma nova abertura onde se reconhece o lugar que eles merecem ter na sociedade, sem que sejam uns sofredores, uns coitadinhos.

Ais poucos, vamos reconhecendo que o excepcional tem o direito de ser como ele é e não, como queremos que ele seja. $O$ deficiente tem potencialidade própria; tudo o que nos pede é que reconheçamos isso. Ele quer participar da sociedade pelo trabalho e, não, pie dade. Seu trabalho e seu estudo têm articulações próprias e pessoais que devem ser respeitadas. Não se trata de aspectos limitados mas, sim, de aspectos próprios. $O$ deficiente tem 0 direito de ser e existir como é. Na medida em que haja pleno reconhecimento de tudo isso, o excepcional terá plena iserção na nossa sociedade. Sabemos que nesta era da tecnologia, da eletrônica, da compu. tação e do trabalho cada vez mais qualificado e sofisticado, a competição se torna mais intensa e o deficiente com mais dificuldades de ajustamento ao esquema sócio-econômico. Mas, à medida que a ciência progride com novas máquinas, deve progredir, também, no domínio da química e estrutura cerebral, de novas aplicações humanas para resolver o problema $\operatorname{dos}_{c}$ excepcionais.

\section{CONSIDERACOES SOBRE OS DESVIOS}

Excepcionalidade e anormalidade são conceitos populares com significados variáveis. Mas, a identificação de individuo excepcional se faz pelo critério de utilidade social (5). "Indivíduo Excepcional" se refere, usualmente, àquela pessoa que difere da média em tal grau que ela é percebida pela sociedade como exigindo especial tratamento educacional, social e vocacional. Estes critérios variam, naturalmente, de cultura para cultura, de uma geração para outra. As variações entre as pessoas são universais mas, a sociedade determina que desvios são considerados prejudiciais ou vantajosos, depreciações ou valorizações do mérito pessoal. As vantagens e desvantagens são ditadas pelas tarefas que uma cultura espera ou exige dos seus membros e pelos significados que atribui aos desvios da norma, como pelos fatos objetivos da excepcionalidade.

Para uma consideração básica, apresentamos, aqui, seis áreas ou modos gerais de desvio (5):

1) Desvio Intelectual - A partír da média temos desvios intelectuais em duas direções. Na parte inferior da escala de inteligência estão os retardados mentais, os casos de fronteira e os apáticos ou deprimidos; na parte superior estão os indivíduos bem dotados ou talentosos.

2) Desvio Sensorial - $O$ sensorialmente excepcional é aquele que apresenta diminuição ou ausência da acuidade visual ou da acuidade auditiva.

3) Desvio Motor - Neste grupo estão os mutilados, os ortopedicamente deficientes e os defeituosos da fala.

4) Desvio da Per:onalidade - Aparecem neste grupo os neuróticos e os psicóticos.

5) De:vio Social - Nos desviados da normalidade social são considerados os delinqüentes juvenis, os criminosos adultos e os culturalmente desfavorecidos.

6) Problema da Velhice - Há problemas de ajustamento próprios desta faixa etária ligados a mudanças físicas, mudanças no funcionamento intelectual e nos interesses e atividades sociais.

Muitas ou mesmo a grande maioria de pessoas excepcionais são excepcionais em mais de uma área.

Todos conhecemos pessoas que são mudas e surdas, cegas e surdas, pessoas com defeitos sensoriais e intelectuais, 
pessoas com deficiências motoras associadas a outros tipos de desvio. difícil para um indivíduo com uma extrema deficiência física, sensorial ou mental não se tornar em certa medida, portador de um desvio social ou da personalidade.

As concepções atuais são quantitativas e concebem as diferenças entre o normal e o excepcional como uma questão apenas de grau. Compreender uma criança diminuída significa, primeiro que tudo, compreendê-la como criança e, só depois, entender as formas pelas quais os seus desvios poderão influenciar o seu desenvolvimento e comportamento. As necessidades sociais, psicológicas e educacionais básicas das crianças excepcionais são idênticas às necessidades de todas as crianças è podem ser satisfeitas, em grande parte, da mesma forma geral, somente diferem nos aspectos específicos. A criança excepcional como qualquer outra criança, pode sentir-se confortável e segura quando se sente aceita, apreciada e amada. Sentir-se-á igualmente intranqüila a insegura quando é rejeitada e depreciada.

\section{A CRIANCAA EXCEPCIONAL}

Desenvolvimento é processo global, harmonioso, onde 0 que 0 indivíduo aprende até $06 .^{\circ}$ ano de vida ocorre na totalidade de seu corpo. Cada peça do organismo, audisão, visão, tato, o corpo inteiro age no trabalho de receber, interpretar, assimilar e armazenar os conhecimentos elaborados dentro do próprio indivíduo e os que adquire do meioambiente. Aprenderá melhor quem estiver com todos os seus sentidos intactos e abertos para receber as informações que vêm do meio-ambiente e que são levadas pelas vias sensoriais até o cérebro que as classifica e determina as respostas a serem dadas (1).

Se pretendemos diminuir o número de crianças excepcionais é urgente e necessário que trabalhemos em níveis de prevenção primária, destacando a assistência à gestante em alto risco, o aconselhamento genético, o diagnóstico precoce, a seleção e o encaminhamento da clientela específica, bem eomo a complementação terapêutica, através dos atendimentos médico, odontológico, farmacêutico para as intercorrências e afecções nẫo específicas do processo de deficiência. imprescindivel que se organize um esquema de estimulação precoce (5) em que se utilize técnicas de intervenção de natureza médicc-psicossocial, baseadas em teorias de aprendizagem e desenvolvimento, aplicadas à criança de 0 a 3 anos, que em decorrência de múltiplos fatores atuantes em período pré, per e pós-natal, apresente alto risco de "deficit" nas áreas sensório percéptica, motora, cognitiva, emocional, de comunicação e adaptação social, objetivando reduzir ou eliminar desvios dos pádrões mínimos de normalidade.

Nossa realidade brasileira é típica de país em desenvolvimento, onde o ritmo de crescimento da população é de 2,9\% ao ano. Em 1980, seremos, aproximadamente 130 milhões de indivíduos. Um dos graves fatos desta realidade é a elevada taxa de mortalidade infantil onde a conjugação da desnutrição, infecção e/ou verminose responde, pelo menos, com $60 \%$ da mortalidade nos primeiros anos de vida (4). bem verdade que a introdução de uma medicina mais moderna melhora as perspectivas de futuro. Mas, pelo menos por enquanto, permanece um sistema social gerador de indivíduos com desnutrição severa (no Brasil há 25 milhões de desnutridos), o que gera outros indivíduos também desnutridos. A distribuição de renda nos parece fator importante na mudança deste círculo vicioso. Se a criança não encontra um meio-ambiente adequado para seu crescimento e desenvolvimento, como poderá fazer sua perfeita integração no desenvolvimento inter e intrasensorial, bases para a aprendizagem? 
SANTOS, M.P. - A criança excepcional. Rev. Bras. Enf.; DF, 33 : 236-241, 1980.

Outros fatores como a carência de estimulação (o isolamento) podem determinar alteração da estrutura e função cerebral. A criança privada dos estímulos adequados ao seu desenvolvimento, por certo, apresentará dificuldades de aprendizagem escolar, pois, as condições do meio-ambiente interferem dramaticamente para o insucesso da aprendizagem. Na atualidade é maior o número de sobreviventes da agressão do meio-ambiente, portanto, maior, também, o número de crianças com desvantagens para aproveitar os avanços da sociedade em que vivem. tógico que os problemas de caráter genético e/ou familiar interferem no número de excepcionais mas, é pequena a porcentagem em comparação com os problemas ambientais (desnutrição, infecções, isolamento).

$O$ interesse pelos superdotados também merece preocupação, pois, a criança brilhante deve ser assistida adequadamente, com programa educacional especial (2). O fato de ser ela capaz de produzir com qualificação superior e originalidade a marginaliza, constituindo-se também um problema sério a sua colocação adaptada na sociedade. necessário que também o superdotado tenha uma educação diferenciada (3), assim como deve ter uma educação diferenciada os subdotados, para que estes e aqueles participem de uma sociedade produtiva onde suas parcelas façam parte de um todo integrado. Se os superdotados, assim como os subdotados, não forem assistidos convenientemente, por certo, ficarão à margem da sociedade, constituindo elementos de desordem social. A sociedade, a escola e a família devem oferecer alternativas capazes de ajustar estes indivíduos no contexto comum (2).

\section{RECURSOS NO ATENDIMENTO AO EXCEPCIONAL NO BRASIL}

Pela Portaria Interministerial número 477, de 11 de agosto de 1977 (3), a responsabilidade de assistêcia aos excepcionais ficou a cargo da Legião Brasileira de Assistência (LBA), encarregada também de fiscalizar o cumprimento das exigências pelas entidades filantrópicas, públicas federais, estaduais e municipais que, através de convênio com a Previdência Social, se proponham prestar serviços especializados de diagnóstico, tratamento e reabilitação de excepcionais, concedendo também auxílios complementares como próteses, órteses, além dos medicamentos indispensáveis no tratamento.

A primeira etapa da nova política é identificar os doentes e os recursos existentes na comunidade, visando prevenir as causas da deficiência mental e minimizar os seus efeitos. Feito isto, os excepcionais são incluídos nos programas especializados que se destinam aos portadores de deficiência física ou psíquica, congênita ou adquirida precocemente e que, entre outros aspectos, apresentem alterações provovadas por estas incapacidades, gerando desvios dos padrões médios. Com o diagnóstico e avaliação das condições físicas, mentais e psico-sensoriais, o excepcional entra num programa de reabilitação, visando sua integração na comunidade.

A clientela alvo desta nova política de assistência ao excepcional é classificada em 5 grupos (3):

GRUPo I - Enquadram-se os portadores de deficiência física de causa neuro-patológica central ou periférica, não progressiva, associada ou não à deficlência mental moderada ou leve.

GRUPO II - Estão os portadures de deficiência mental, de leve a moderada, associada ou não a uma deficiência física, não paralítica, que afete simultaneamente a capacidade intelectiva e a performance motora da coordenaçăo dos movimentos.

GRUPo III - Enquadram-se os excepcionais portadores de distúrbios do comportamento de causa psico-patológica central ou de perturbações da pst- 
SANTOS, M.P. - A criança excepcional. Rev. Bras. Enf.; DF, $33: 236-241,1980$.

comotricidade que afetem a capacidade de falar, a capacidade de aprendizagem e/ou o relacionamento social afetivo.

GrOPO IV - Ficam os portadores de deficiência física, relacionada com uma afecção muscular ou articular, ou com alterações do aparelho locomotor.

GruPo V - Estão os portadores de deficiência auditiva ou visal, parcial ou total, associada ou não a qualquer das outras deficiências (intelectual, da psi. comotricidade e/ou do aparelho locomotor).

Nesta classificação se incluem, também, o tratamento precoce de criança nascida de pais reconhecidamente transmissores de alterações genéticas, aquelas cujas mães tiveram gravidez de alto risco ou parto distócico, as crianças que tenham tido nasctmento prematuro seguido de má evolução e, também, a criança que nos primeiros dias de vida apresentaram complicações clínicas, alteraçōes nos reflexos ou em seu estado geral (3).

Esta nova visão da política de assistêncla ao excepcional é realmente uma conquista, após tantos anos de luta e dedicação de um grupo de educadores, médicos, psicólogos, assistentes sociais, Juristas e colaboradores ocasionals. um plano de assistência com objetivos gerals definidos, incluindo: 1) Atendimento especializado de natureza médico-psico-social e educacional; 2) Prevenção de deficiências ou minimização dos defeitos já instalados mediante processo de diagnóstico e atendimento precoce; 3) Continuidade de atendimento, através da oferta de serviços especializados de reabilitaãço e educação; 4) $\mathrm{Ga}$ rantia do padrão mínimo de qualldade nos serviços especializados com permanente supervisão e controle; 5) Possibilidade de atendimento integral do excepcional, adotando ação integrada em termos das várias áreas de atuação do EC e MPAS e das iniciativas pública e particular (3).

\section{PERSPECTIVAS DE FUTURO}

Os organismos internacionais como a UNESCO, Organização das Nações Unidas, a Organização Internacional do Trabalho, a International Rehabilitation analisam as novas diretrizes, linhas políticas de ação, reforçando as idéias de integração no atendimento aos excepcionais. Muitos países já mostraram sua contribuição tecnológica, principalmente quanto à educação de deficientes físicos, visuais e auditivos, no uso de novos recursos de próteses, material de ensino, etc. (4). Enfatiza-se também, no momento, a importância da mudança de atitudes frente aos novos princípios da educação especial. Há uma preocupação transdisciplinar dos educadores e especialistas em tornar cada vez mais a educação especial dentro de uma visão sistêmica, integrada na educação geral. A criação do Centro Nacional de Educação Especializada (CENESP) deu novo rumo à problemática do preparo do pessoal docente e técnico para a educação de excepcionais, visando a expansão e melhoria quantativa e qualitativa do atendimento prestado (4). Neste programa estão incluídos tantos os deficientes como os superdotados.

Apesar das dificuldades de um país como o nosso, com características tão diferentes em suas diversas regiōes, há a preocupação permanente de preparar pessoal com a finalidade de melhor atendimento ao excepcional dentro dos princípios atuais de normalização, integração, prevenção, continuidade e inovação, proporcionando ao excepcional a formação necessária ao desenvolvimento de suas potencialidades como fator de auto-realização, qualificação para o trabalho e preparo para o exercício consciente da cidadania.

\section{CONCLUSAO}

A criança excepcional precisa e merece ser aceita como ela é, respeitandose sua potencialidade própria. 
SANTOS, M. P. - A criança excepcional. Rev. Bras. Enf.; DF, 33 : 236-241, 1980.

A criança excepcional tem necessidades sociais, psicológicas e educacionais como as crianças normais e, portanto, podem ser satisfeitas em grande parte, do mesmo modo geral, variando apenas os aspectos específicos.

$O$ meio-ambiente tem forte influência no adequado desenvolvimento, embora fatores de caráter genético e/ou familiar interfiram no número de excepcionais.

Os deficientes, como também os superdotados, necessitam de educação especial para que, num sistema de ensino regular e com apoio técnico, tenham condições de se integrar estes excepcionais nas classes comuns.

O MPAS e o MEC são responsáveis pelo planejamento e implementação de programas de atendimento aos excepcionais, somando esforços no sentido de integrar o indivíduo excepcional numa sociedade onde as oportunidades de crescimento individual e coletivo serão dadas também àqueles que são "diferentes".

Para cada um de nós sobre a responsabilidade do interesse e iniciativa para favorecer a integração do excepcional à nossa sociedade.

\section{REFERENCIAS BIBLIOGRÁFICAS}

1. GRUSPUN, H.: A Familia e Ambiente do Excepcional - Revista "Psiquiatria Atual" - Setembro de 1972.

2. MEDEIROS, N. R.: O Superdotado como Agente Acelerador do Desenvolvimento - RBEn, DF, 31: 312-320, 1978.

3. MPAS: Ministério da Previdéncia e Assistência Social - Assistência aos Excepcionais e Portaria Interminis- terial n.o 186, de 10 de março de 1978 - Portaria Interministerlal n. ${ }^{\circ}$ 477, de 11 de agosto de 1977 - Portaria n. ${ }^{\circ} 08$, de 21 de março de 1978.

4. PESTALOZZI - Órgåo Ofilcal da Federação Nacional das Sociedades Pestalozzi - FENASP. Maia-agosto de 1978.

5. TELFORD, Charles; SAWREY, James M.: The Exceptional Individual, New Jersey, U.S.A. - 1972. 